\title{
Residual Stresses in Bonded Armor Tiles for In-Vessel Fusion Components
}

\author{
J.P. Blanchard \\ University of California, School of Engineering and Applied Science, \\ 6291 Boelter Hall, Los Angeles, California 90024, U.S.A. \\ R.D. Watson \\ Sandia National Laboratories, Division 6248, P.O. Box 5800, Albuquerque, \\ New Mexico 87185, U.S.A.
}

\section{ABSTRACT}

The residual stresses in a bonded tile/substrate structure were analyzed using both analytical and finite element methods.

Beam theory and 2-D elasticity solutions were compared and the latter was found to be more accurate, due to inadequate boundary conditions used in beam theorles. Agreement between analytical elasticity and finite element solutions was favorable, but the increased flexibility of finite element codes makes them superior when non-linear problems are considered.

The response of the calculated stress states to changes in various model dimensions and material parameters was studied parametrically. In general, dimensional changes were found to be significant only for short, thin tiles.

\section{INTRODUCTION}

The attachment of ceramic or refractory armor tiles to in-vessel components by brazing or diffusion bonding has been identifled as a critical issue for the next generation of fusion devices. These tiles must withstand severe thermal gradients and eddy current-induced forces from plasma disruptions without debonding from the heat sink. It is important therefore, to minimize the residual stresses that develop at the bond Interface during cooldown from the bonding temperature. These stresses, resulting from the mismatch in the thermal expansion coefficients of the tile and substrate, can easily exceed the tiles' strength leading to signiflcant yielding and/or cracking. Careful design, however, can minimize the impact these residual stresses will have on the rellabllity of the component.

The complexity of the stress distribution caused by bonding at elevated temperatures requires a thorough analysis for proper characterization. Previous attempts [1-4] have used classlcal beam theory to analyze the problem of uniform temperature change in a laminate, while Ochoa and Marcano[5] modified the theory to include transverse shear deformations. The major drawback to these analyses is that the boundary conditions require only the forces on the laminates free surface to go to zero, rather than the stresses. This leads to (incorrect) predictions that the shear stress in the bond layer peaks at the surface. More complete solutions are offered by Chen, Cheng, and Gerhardt[6] and Ishai and Gali[7]. Chen, et.al., use 2-D elasticity theory and the 
variational theory of complementary energy to obtain an approximate, closed-form solution that satisfies the proper, zero-stress boundary conditions. Ishai and Gall use finite element methods to analyze a unique, mult1-layer model, which features very thick adhesive layers. Unfortunately, this type of model ylelds limited information for fusion applications because brazing and diffusion bonding involve very thin layers.

The following paper utilizes finite elements to compare the avallable analytical solutions and study the effect that changes in the model dimensions and material parameters have on the associated stress flelds.

\section{COMPARISON OF SOLUTION METHODS}

To facilitate comparison of the three primary methods of calculating residual interlaminar stresses, the model analyzed by Chen, et al., will be studled. As seen in figure 1, the model consists of two primary layers (t1le and substrate) of equal width with different material properties. These are joined by a thin interlayer of a third materlal. The elastic stress distributions due to a uniform, $100^{\circ} \mathrm{C}$ temperature rise will be determined using the parameters in table 1.

As seen in figures 2 and 3 , the two analytical solutions for the interlaminar stress distributions differ markedly. The predicted normal stresses $\left(\sigma_{y}\right)$ have a similar form, but the beam theory results peak about 2.5 times higher than the 2-D elasticity results. The shear stresses, $\tau_{x y}$, exhibit an even greater discrepancy, due to the incomplete boundary conditions used in the beam theories. It should be noted that 2-D elasticity theory [6] does indeed predict a non-zero shear stress at the interface of two dissimilar materials, such as between the bond layer and the tile. This is due to the discontinuity in the material properties. Away from such discontinulties, though, the shear stress always vanishes at a free surface. This leads one to belleve that elasticity calculations, which demand that this condition be met, are more rellable.

ABAQUS, a finite element code, was used to analyze the same model and the agreement with the elastlclty solution was favorable. Due to the large stress gradients near the free surface, a relatively fine mesh was needed to obtain an accurate solution, in which the shear stress approached zero at the end. Flgure 4 shows that the finest of the analyzed meshes predicts a peak shear stress comparable to the 2-D elasticlty solution. The major difference is in the location of this peak. This relatively minor difference is probably due to errors in the assumed displacement patterns of each solution. It appears, though, that finfte element methods can be relied upon to give accurate results for Interlaminar stresses, provided that sufficient care ls taken in meshing the model.

\section{PARAMETRIC STUDIES}

The model of figure 1 was also used to study the role that it's dimensions and matcrial properties play in creating the complex residual stresses of figures 2 drid 3 . Rather than using the properties suggested in reference [6], the bonding of graphite tiles to a copper heat sink with a silver interlayer was analyzed.

The first parameter adfusted is the model length, $2 \ell$. Since the stresses are localized at the ends, one might conclude that the model could be shortened considerably before the stress flelds interact, thus altering their distribution. Th1s is verified in 
figure 5, which shows the peak graphite stresses near the bond layer for various length-to-thickness ratios. As seen, the total model length must be less than the half-thicknesses before any reduction in the stress is realized. This indicates that the tiles must be short compared to their thickness, if elastic stresses are of a concern.

It is also interesting to note the effect of changing the graphite layer thickness, maintalning the model half-length $(\ell)$ and copper thickness at $5 \mathrm{~cm}$. As seen in flgure 6 , decreasing the tile thickness can reduce $T_{x y}$ and $\sigma_{y}$, but it may actually increase $\sigma_{x}$. This anomaly is not predicted by beam theory and it could be significant in some designs.

The final parameter studied was the tile modulus. As the graphite modulus was doubled and quadrupled, $\sigma_{y}$ and $\tau_{x y}$ did not increase linearly in the graphite (figure 7). This indicates that the high modulus of tungsten may not be as harmful to 1t's prospects as a tile material as one might expect.

\section{CONCLUSION}

Resldual stresses due to brazing or diffusion bonding can significantly Impact component design. Because of the complexity of the stress distributions, beam theory solutions inadequately model the problem and 2-D elasticity calculations are too lengthy for any but the simplest problems. Therefore, finite element methods were found to be the best tool for computing interlaminar stresses, especlally when temperature dependent properties and plastic deformations are included. Proper choice of the mesh, though, is critical.

\section{ACKNOWLEDGEMENT}

Thls research was performed under appointment to the Magnetlc Fusion Energy Technology Fellowship Program administered by 0ak Ridge Associated Universities for the U.S. Department of Energy. The work was performed at Sandia National Laboratories, with additional support under U.S. DOE Contract No. DE-Ac04-76DP00769.

\section{REFERENCES}

[1] Timoshenko, S., "Analys1s of Bi-Metal Thermostats", J. Strain Anal., 11, 233-255, 1926.

[2] Grimado, P.B., "Interlaminar Thermoelastic Stresses in Layered Beams", J. Thermal Stresses, 1, 75-86, 1976.

[3] Chen, W.T., and Nelson, C.W., "Thermal Stresses in Bonded Joints", IBM J. Res. Dev., 23, 179-168, 1979.

[4] Williams, H.E., "Thermal Stresses in bonded Solar Cells - The Effect of the Adhesive Layer", J. Thermal Stresses, 6, 231-252, 1983.

[5] Ochoa, 0.0., and Marcano, V.M., "Thermal Stresses in Laminated Beams", Int. J. Sollds Structures, 20, 574-587, 1984.

[6] Chen, D., Cheng, S., and Gerhardt, T.D., "Thermal Stresses in Laminate Beams", J. Thermal Stresses, 5, 67-84, 1982.

[7] Tshai, 0., and Gali, S., "Two-Dimensional Interlaminar Stress Distribution with1n the Aahesive Layer of a Symmetric Doubler Model", J. Adhesion, 6, 301-314, 1974. 
[8] Bogy, D.B., "On the Problem of Edge-Bonded Elastic Quarter-Planes Loaded at the Boundary", Int. J. Sollds Structures, 6, 1287-1313, 1970.

[9] Hibbit, Karlsson and Sorenson, Inc., ABAQUS User's Manual, ProvIdence, RI, 1984.

\section{TABLE I}

$$
\begin{array}{llll}
\mathrm{E}_{1}=2.07 \times 10^{5} \mathrm{MPa} & v_{1}=.25 & \alpha_{1}=6.5 \times 10^{-60} \mathrm{C}-1 \\
\mathrm{E}_{2}=.69 \times 10^{5} \mathrm{MPa} & v_{2}=.33 & \alpha_{2}=13.0 \times 10^{-6} \mathrm{C}^{-1} \\
\mathrm{E}_{3}=.30 \times 10^{5} \mathrm{MPa} & v_{3}=.33 & \alpha_{3}=2.5 \times 10^{-60} \mathrm{C}^{-1} \\
\ell=25 \mathrm{~cm} & \tau_{1}=\tau_{2}=5 \mathrm{~cm} & n=.1 \mathrm{~cm}
\end{array}
$$

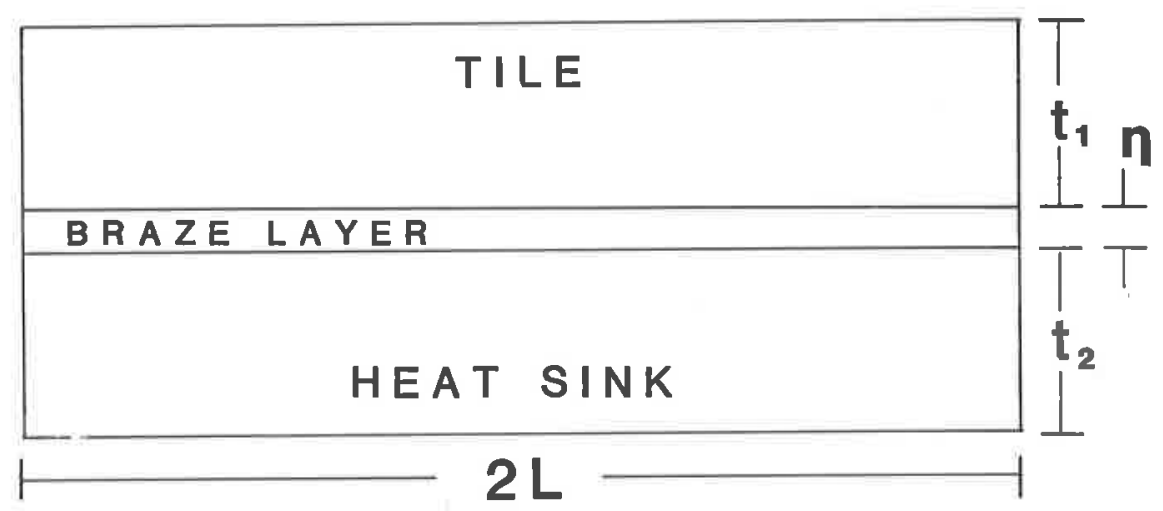

1) Model for residual stress analysis 


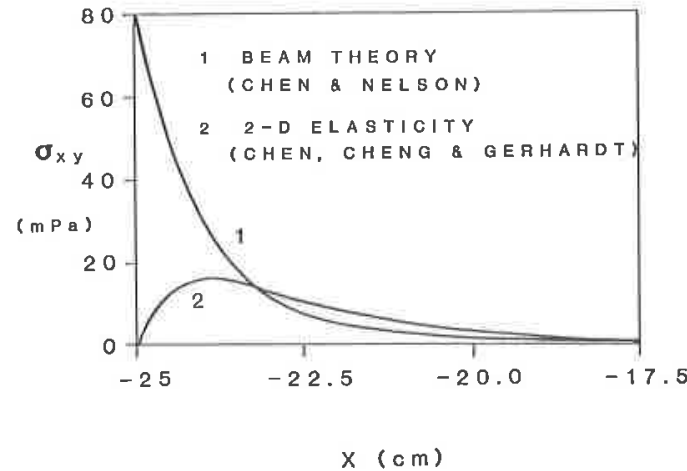

2) Shear stresses in bond layer for 2-D elasticity and beam theory solutions

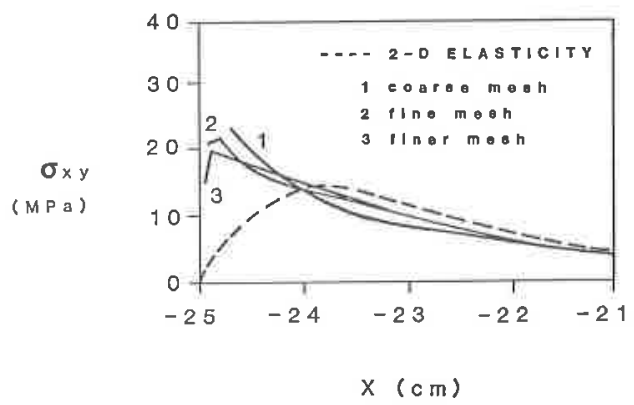

4) Comparison of calculated shear stresses in bond layer for 2-D elasticity solution and three finite element meshes

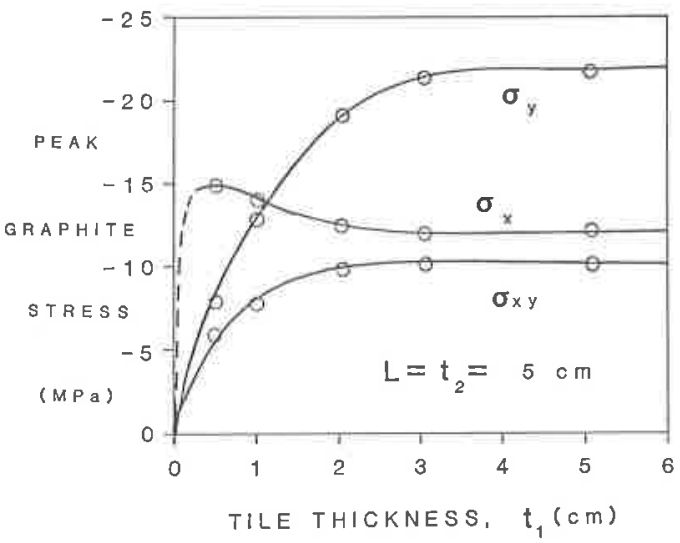

6) Effect of changing tile thlckness on peak stresses in bond layer

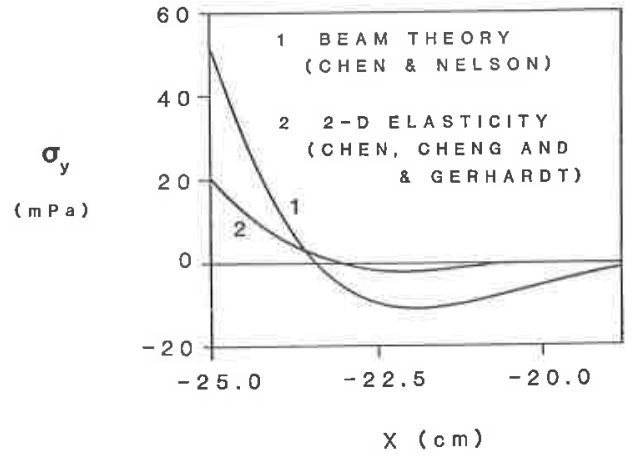

3) Normal stresses in bond layer for 2-D elasticity and beam theory solutions

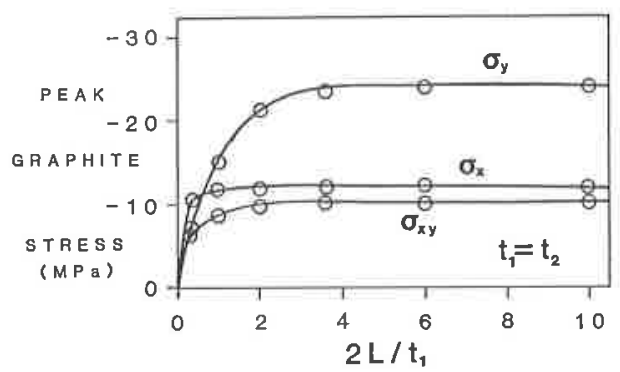

5) Effect of changing model length, $\ell$, on peak stresses in bond layer

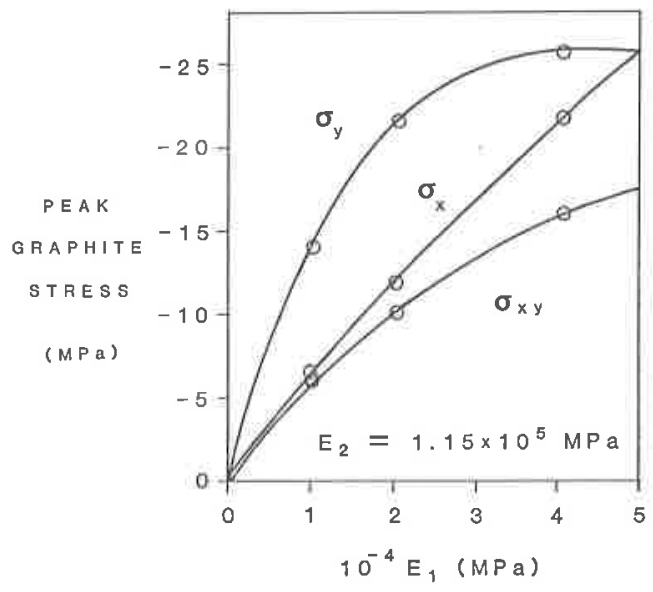

7) Effect of changing tile modulus on peak stresses in bond layer 